\title{
Comparative Study of Methods Used for a Capacity Estimation on Two Lane Undivided National Highways
}

\author{
Vijay B. G. and Rajendra Khatavkar \\ MVJ College of Engineering, Bangalore, India
}

\begin{abstract}
In these days the traffic is expanding quickly and the activity conditions on Indian roads are exceedingly heterogeneous in nature because of variety of vehicles with various static and dynamic qualities. Due to unrestricted movements all fast and slow moving vehicles without any separation, the roads will face severe congestion and lower speeds. The greater part of national and state highways in India are two lane undivided roadway. These two lane highways achieve its greatest limit soon and require consistent up gradation to do this we need to estimate capacity of selected roads. In this present paper, attempts have been made to collect traffic volume for whole 7 days at national highways such as NH-206\& NH-209. Also tried to compute PCU values at selected stretches on highways by using those values attempts has been made to estimate capacity and to compare those values with the regression equation values. Finally from the present study we got ADT at different section on highways, calculated PCU values as per Chandra's method at various sections on highways and got marginal difference with the values recommended by IRC. It is found that with the increase in lane width, speed and radius substantially caused increased in PCU value. Also we developed linear regression equations to estimate capacity and compared those values with the values as we got using Chandra's method. In most of the cases the error is observed to be less than $3 \%$. The percentage error is in the range between 0.02 and 2.41 which is very marginal. Finally from the study it has been observed that increase in lane width and radius at curves obviously increases the capacity their by increases both comfort and safety of the road users.
\end{abstract}

Key words: Traffic volume count, PCU, mean speed, capacity, linear regression equation.

\section{Introduction}

India has the second largest road network in the world (3.3 million $\mathrm{km}$ ). Current affair of the Indian highways total length is $55,000 \mathrm{~km}$ in that which $66 \%$ of roads are two lane facilities with varying lane width but still India is facing enormous difficulties in providing better vehicular traffic flow and operations. The main source of transportation in India is by road. Rapid and continuous increase population is major problem for highway engineers. Due to increase in population the different modes of transportation are increases in cities which are resulted in jammed traffic condition on road. Roads play an important role in the transportation of goods and passengers for short medium distances and road transport is more flexible than other modes of transport. But now a day the traffic conditions on Indian roads are highly heterogonous in

Corresponding author: Vijay B. G., M.Tech; research fields: traffic engineering, and pavement materials. nature due to variety of vehicles with different static and dynamic characteristics.

Expectation and learning of capacity are essential in the design, planning, operation, and design of road geometrics. Among different things, these give the premise to deciding the lane width and number of lanes to be provided anytime in a road connects concerning the volume and creation of movement. They are profitable apparatuses for the assessment of the ventures. Separated from different parameters, limit is significantly impacted by roadway also, driver conditions. Roadway variables may incorporate the majority of the geometric parameters depicting the highway including the sort of office, lane width, lateral clearance, and width of shoulders also horizontal and vertical alignment of the road. Lane and shoulder widths can substantially affect on mixed traffic movement. On limit lanes, vehicles set out nearer to each other horizontally. This may lessen their speed or increment the longitudinal gaps. The capacity is 
decreases in both situations.

The present study was undertaken to identify the effect of lane width, average spot speed of different vehicles and standard projected area of different vehicles on the capacity of a two- lane road under heterogeneous traffic conditions. Data were collected at different sections of two lane highways (NH-206 \& $\mathrm{NH}-209)$ with the carriageway width ranging from 7.0 to $9.8 \mathrm{~m}$ by considering both straight as well as horizontal curve portions.

\section{Objectives}

Collection of traffic volume for 12 hours whole week at straight and curved sections of two lane undivided national highways (NH-209 and NH-206).

Collecting geometric details of different categories of roads and finding out dynamic (average spot speed) and Static (standard rectangular area) behavior of vehicles.

Determination of PCU values at different sections of roads and comparing these values with lane width, spot speed and horizontal curve radius.

Capacity estimation by using Chandra's method and development of regression equations and their comparative statement.

\section{Literature Review}

For estimation of capacity there are many extensive researches were found and literature review are listed.

Dr. Satish Chandra and UpendraKumar [1] in their paper "Effect of lane width on capacity under mixed traffic conditions in India" showed the relationship between PCU and capacity values by change in carriageway width. By using this relationship a derived the adjustment factors for sub standard lane widths and the results are compared with literature. A R Khanorkar et al. [2] in their paper "Impact of lane width of road on Passenger Car Unit capacity under mix traffic condition in cities on congested highways" found out PCU values at different sections on highways and concluded in such a way that PCU values of vehicles significantly changes with change in traffic volume and width of roadway. Hemanth M Kamplimath [3] in his paper "Capacity estimation for A two lane undivided carriageway-A case study for national highway -63" explains the complete process of capacity estimation of and also he suggested the year at which the road may reach its maximum capacity. Their by we may know prioritization in the upgradation of highways. Dr. Tom $\mathrm{V}$ Mathew [4] (IIT Bombay) in his paper "Measurement at a point" explains the procedure about various types of volume counts and counting techniques. Along with this to brief inside into various methods of calculating passenger car unit has been provided. Finally he concluded, Chandra's method is the only method that can be applied to the Indian conditions of heterogeneous traffic. Kay Fitzpatrick et al. [5] in their paper "Summary of comparison of crashes on Rural Two-Lane and Four-lane highways" in Texas offers the variation of capacity parameters. Farouki and Nixon [6] concentrated on "The impact of the carriageway width" explained the speed and capacity varies according to road width. Amr Shalkamy et al. [7-9] in their paper "Influence of carriageway width and horizontal curve radius on PCU values of Two lane undivided Rural roads" studied the influence of different geometric features of tangent and curved elements of PCU values on 2-lane two way rural roads. PCU values for estimated using the speed -area method. Using regression analysis, different models were developed to model the influence of different geometric features on PCU values.

\section{Methodology}

Study Location: The area of location is selected between Bangaluru-Kollegal and Tumkur-Tipatur national highways. The study of location and details of map is show in Figs. 1 and 2. In this study, the various parameters related to capacity effects, have been evaluated on two different national highways (NH206 and NH209) at different sections of Roads. The NH-209 starts from Bengaluru (Kanakpura exit main road) to 


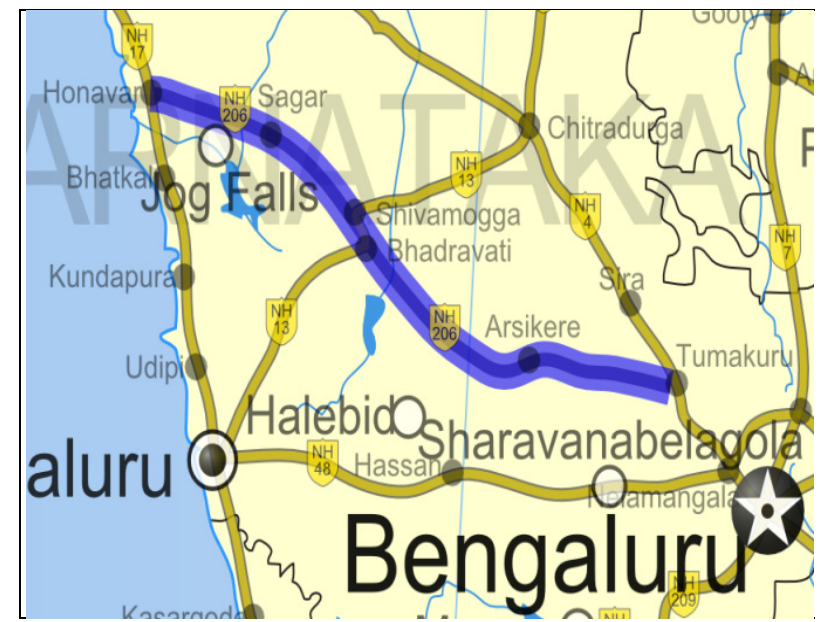

Fig. 1 NH-206 (Tumkur to Honnavara).

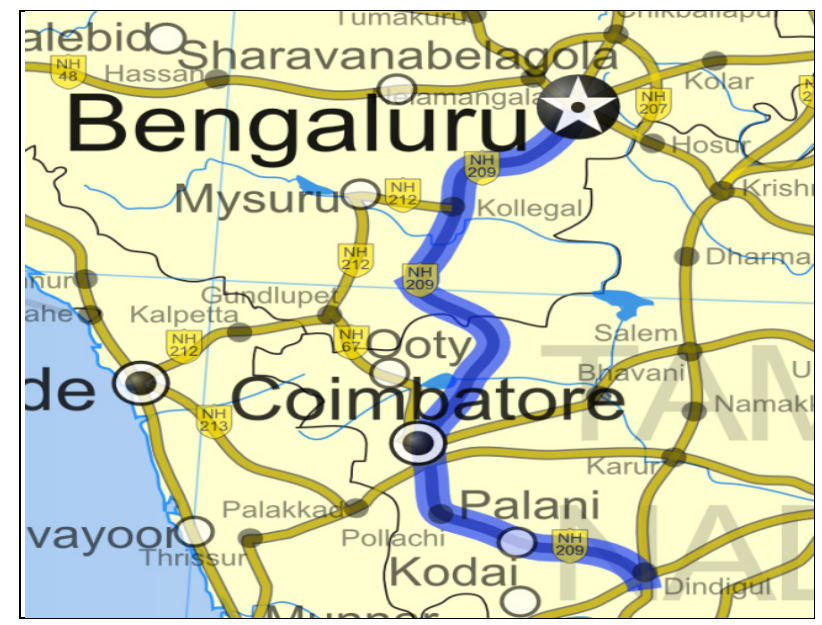

Fig. 2 NH-209 (Bengaluru to Tamil Nadu).

Tamil Nadu border (Dindigul bypass) of distance $486 \mathrm{~km}$ and NH-206 starts from Tumkur (Tumkur-Honnavara bypass) to Honnavara of distance $363 \mathrm{~km}$.

Field data Collection: The physical data is collected manually at selected highways NH209 and NH-206 at 12 different sections ( 6 sections at curve and 6 sections at straight portion). The details of the carriageway width, type of shoulders and width of shoulders are collected from the field. The different sections were selected for capacity estimation.

The details of study stretches are show in Table 1:

Estimation of passenger car unit: The British practice were generally to express capacity in the different types of vehicles suggest different degree of interference to the other traffic and it is required to take all types to a common unit called as passenger car unit (PCU).

To estimate the PCU values is that it is directly proportional to the proportion of clearing speed of vehicle, and inversely proportional to the space occupancy ratio of vehicle with respect to the standard area of vehicle, i.e. a car,. The PCU of a vehicle can be determined using the formula given by Dr. Satish Chandra and Kumar.

$$
P C U=\frac{V c / V i}{A c / A i}
$$

where,

$$
\begin{aligned}
& P C U=\text { Passenger Car Unit value of } \mathrm{i}^{\text {th }} \text { type vehicle } \\
& V_{c}=\text { speed of car }(\mathrm{kmph}) \\
& V_{i}=\text { speed of } \mathrm{i}^{\text {th }} \text { type of vehicle }(\mathrm{kmph}) \\
& A_{c}=\text { static (projected rectangular area) area of a car }\left(\mathrm{m}^{2}\right)
\end{aligned}
$$


Table 1 Geometric details of different stretches.

\begin{tabular}{|c|c|c|c|c|c|c|c|c|}
\hline SL.NO & $\begin{array}{l}\text { Type and number } \\
\text { of lanes }\end{array}$ & Portion & $\begin{array}{l}\text { Category of } \\
\text { road }\end{array}$ & Sections & $\begin{array}{l}\text { Carriageway } \\
\text { width }(\mathrm{m})\end{array}$ & Radius (m) & $\begin{array}{l}\text { Type of } \\
\text { shoulder }\end{array}$ & $\begin{array}{l}\text { Shoulder } \\
\text { width }(\mathrm{m})\end{array}$ \\
\hline 1 & \multirow{6}{*}{$\begin{array}{l}\text { Undivided } \\
\text { (2-Lane) }\end{array}$} & \multirow{6}{*}{ Curve } & \multirow{4}{*}{ NH209 } & Section $-\mathrm{I}$ & 7.4 & 87 & Earthen & 4.1 \\
\hline 2 & & & & Section -II & 7.6 & 91 & Earthen & 3.9 \\
\hline 3 & & & & Section -III & 7.2 & 87 & Earthen & 3.0 \\
\hline 4 & & & & Section -IV & 9.8 & 102 & Earthen & 2.3 \\
\hline 5 & & & \multirow[t]{2}{*}{ NH206 } & Section - V & 9.2 & 95 & Earthen & 2.4 \\
\hline 6 & & & & Section -VI & 8.0 & 91 & Earthen & 3.2 \\
\hline 7 & \multirow{6}{*}{$\begin{array}{l}\text { Undivided } \\
\text { (2-Lane) }\end{array}$} & \multirow{6}{*}{ Straight } & \multirow{4}{*}{ NH209 } & Section - I & 7.2 & - & Earthen & 3.8 \\
\hline 8 & & & & Section - II & 7.4 & - & Earthen & 3.5 \\
\hline 9 & & & & Section - III & 7.0 & - & Earthen & 2.8 \\
\hline 10 & & & & Section - IV & 9.6 & - & Earthen & 2.0 \\
\hline 11 & & & \multirow[t]{2}{*}{ NH206 } & Section - V & 9.0 & - & Earthen & 2.1 \\
\hline 12 & & & & Section -VI & 7.8 & - & Earthen & 2.6 \\
\hline
\end{tabular}

Table 2 Vehicle categories and Projected Area.

\begin{tabular}{|c|c|c|c|c|}
\hline \multirow{2}{*}{ Category } & \multirow{2}{*}{ Vehicle } & \multicolumn{2}{|c|}{ Dimension } & \multirow{2}{*}{ Projected area $\left(\mathrm{m}^{2}\right)$} \\
\hline & & Length $(\mathrm{m})$ & Width (m) & \\
\hline$\overline{\mathrm{CAR}}$ & CAR, JEEP, VAN & 3.72 & 1.44 & 5.39 \\
\hline BUS & BUS & 10.10 & 2.43 & 24.74 \\
\hline TRUCK & TRUCK & 7.50 & 2.35 & 17.62 \\
\hline LCV & MINI BUS/TRUCK & 6.10 & 2.10 & 12.81 \\
\hline M TRUCK & MULTI AXLE TRUCK & 2.36 & 12.0 & 28.60 \\
\hline BIKES & SCOOTER, MOTORBIKE & 1.87 & 0.64 & 1.20 \\
\hline AUTO & AUTO, TEMPO & 3.20 & 1.40 & 4.48 \\
\hline CYCLE & PEDAL CYCLE & 1.90 & 0.45 & 0.85 \\
\hline
\end{tabular}

$A_{i}=$ static (projected rectangular area) area of a $i^{\text {th }}$ type of vehicle $\left(\mathrm{m}^{2}\right)$

The PCU values for different category of vehicles were calculated at different sections of highways. This calculated value shows the difference in PCU for different category of vehicles with path width at different section. The PCU factor is based on the mean speed values of different vehicle classes.

\section{Results and Discussions}

The manual traffic volume count is done for 12 hours (7:00 a.m. to 7:00 p.m.) at six different sections and 7 days traffic is converted into average daily traffic (ADT) by considering both the direction. Hourly variations for the sections are as shown below:

The percentage composition of vehicles by considering average 7 days traffic on NH-206 and NH-209 which is as shown in Fig. 4:
After seven days of volume count the average percentage sharing of vehicles on both the national highways in the total volume shows majority of two wheeler's i.e. $50 \%$, followed by 335 of cars , $10 \%$ of LCV, 3\% of Buses and 3\% of HCV's as indicated.

Speed is the most important characteristics of traffic for determination of PCU and capacity. The average speed of all vehicles at different sections is determined. The variation of speed by change in lane width and radius at curves are shown below and it is found to be varying as the lane width increases as well as radius at the curved portions.

After getting the average speed value of vehicles PCU can be determined.

EX: PCU of Bus, $P C U=\frac{56 / 47}{5.34 / 24.74}=5.52$

Similarly calculation of PCU for other vehicles by same procedure has been done. 


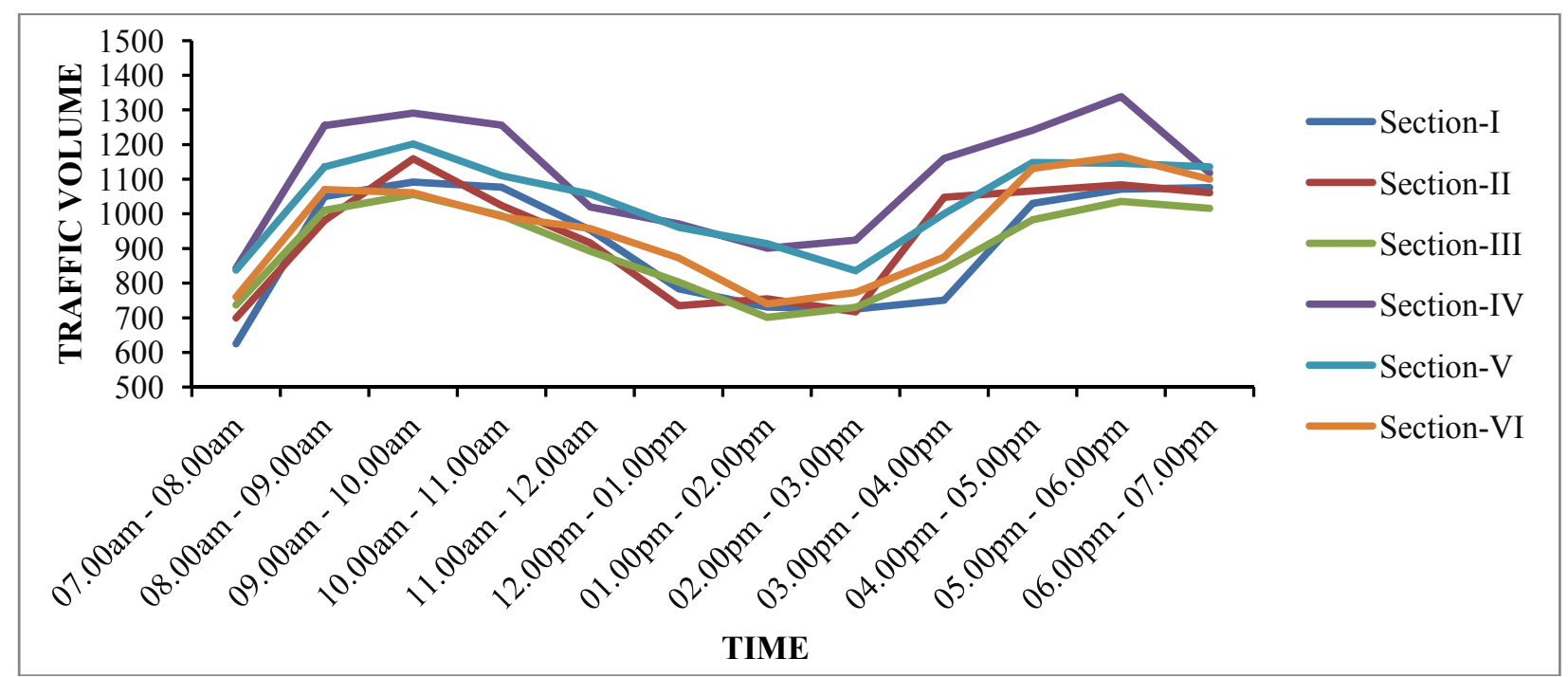

Fig. 3 Hourly traffic volume variation at all sections.

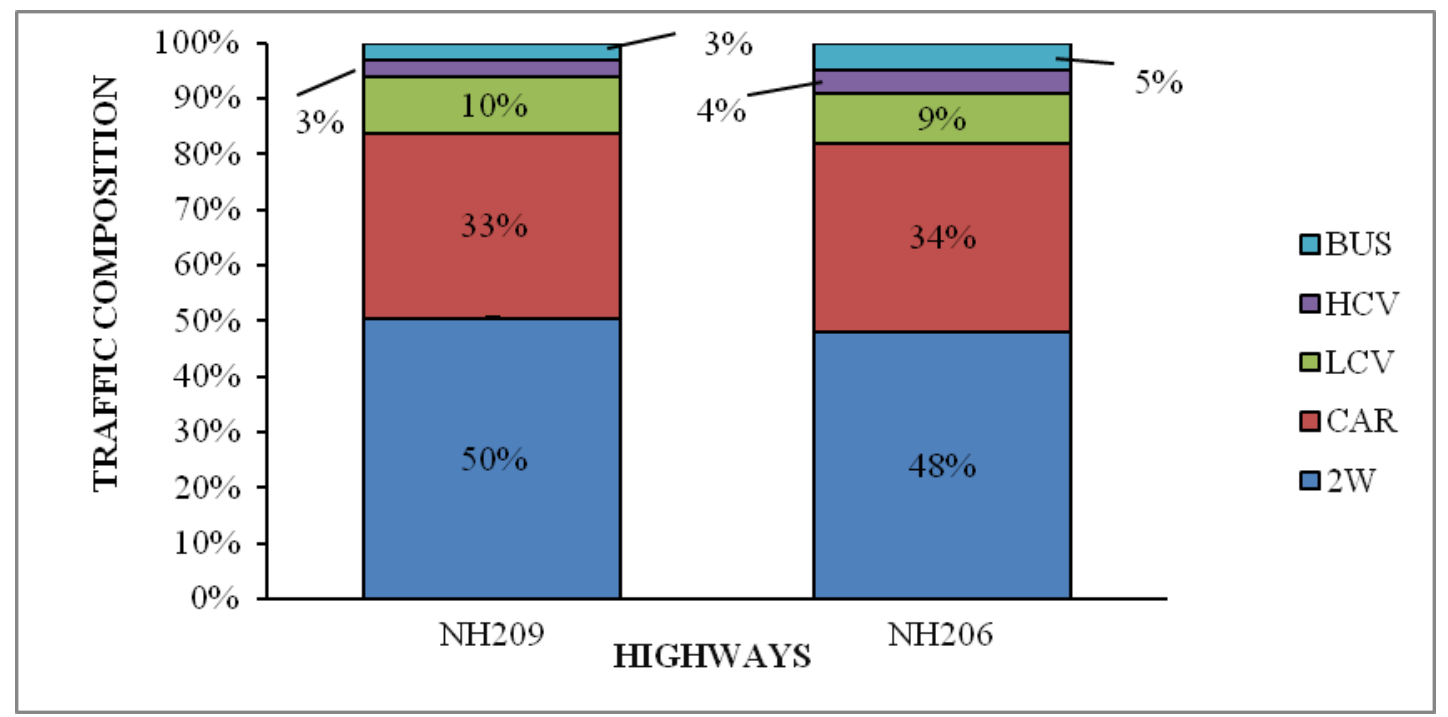

Fig. 4 Percentage shares of different types of vehicles on highways.
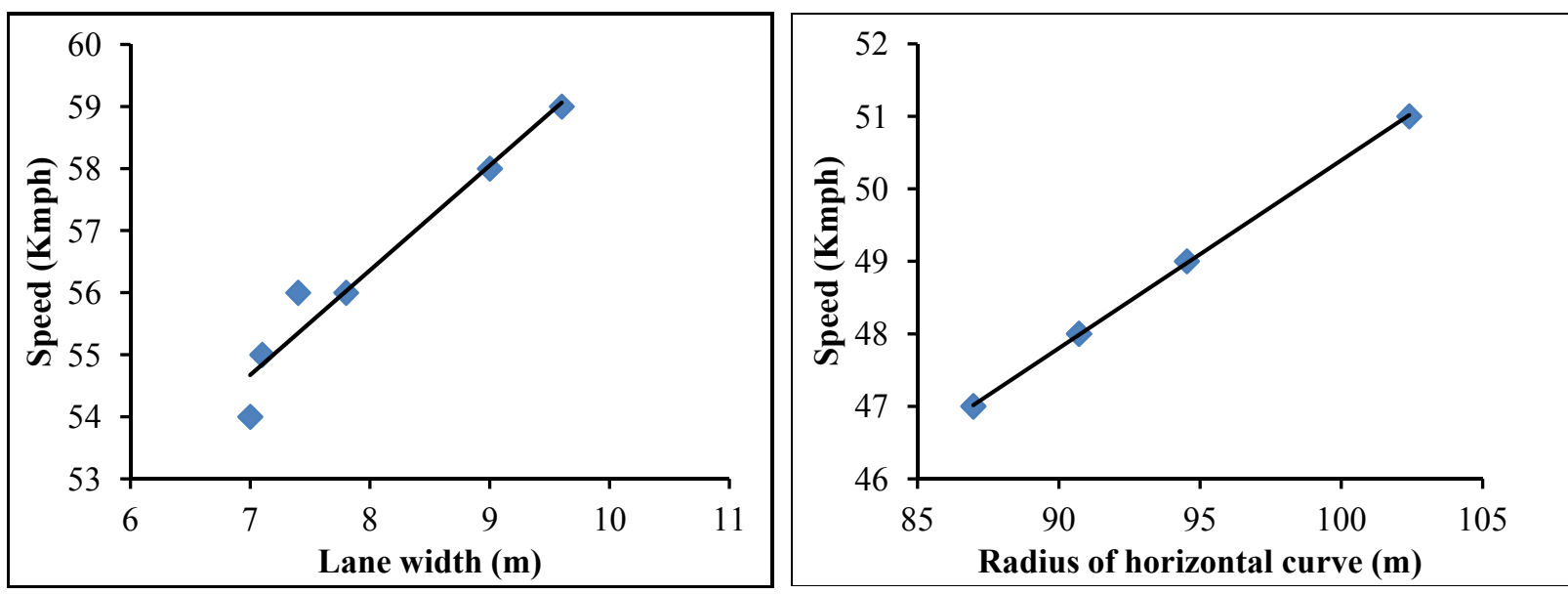

Fig. 5 Speed vs. Lane width and Radius of horizontal curve. 

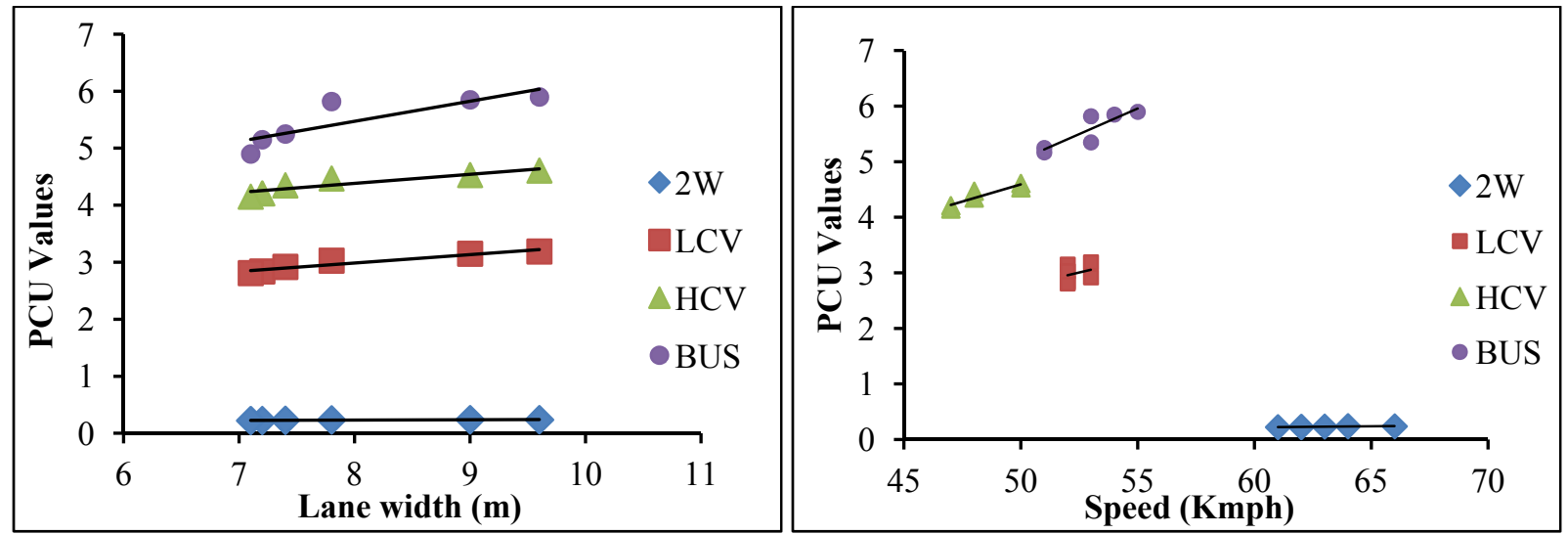

Fig. 6 PCU values vs. lane width and speed at straight portion.
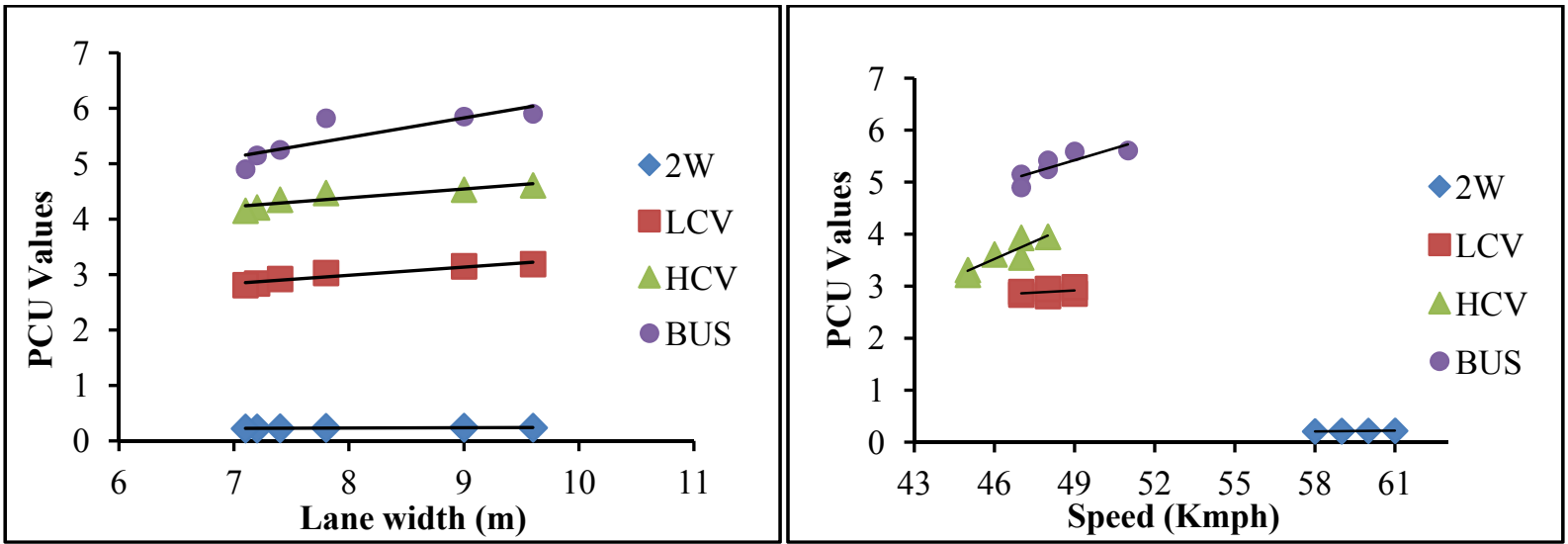

Fig. 7 PCU values vs. lane width and speed at horizontal curve portion.

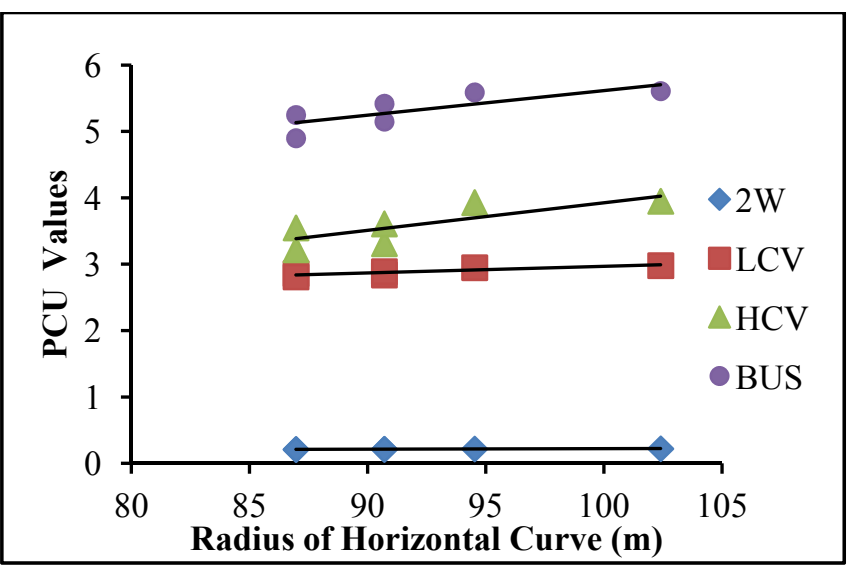

Fig. 8 PCU values vs. radius at horizontal curve portion.

The variation of PCU Values of different category of vehicles by change in lane width, average speed (for straight and curved portion) and radius of horizontal curve are as shown below:

PCU values for different types of vehicles at different sections on highways (NH-209 and NH-206) were found out as per Satish Chandra's method and is observed values are varying depending upon lane width, speed, and radius of horizontal curve.

Attempts have been made to develop linear regression equation to obtain capacity for two lanes undivided national highways based on lane widths, speed and radius of horizontal curves individually. The equations obtained are as follows: 


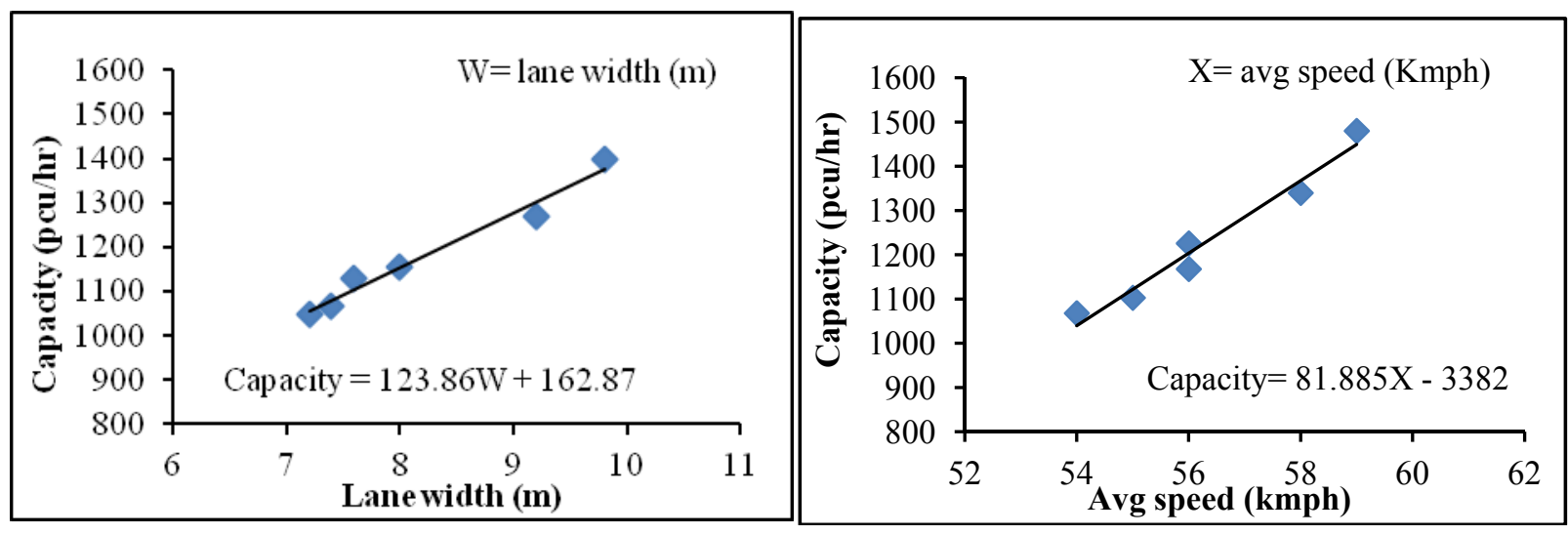

Fig. 9 Capacity vs. lane width and average speed at straight portion.
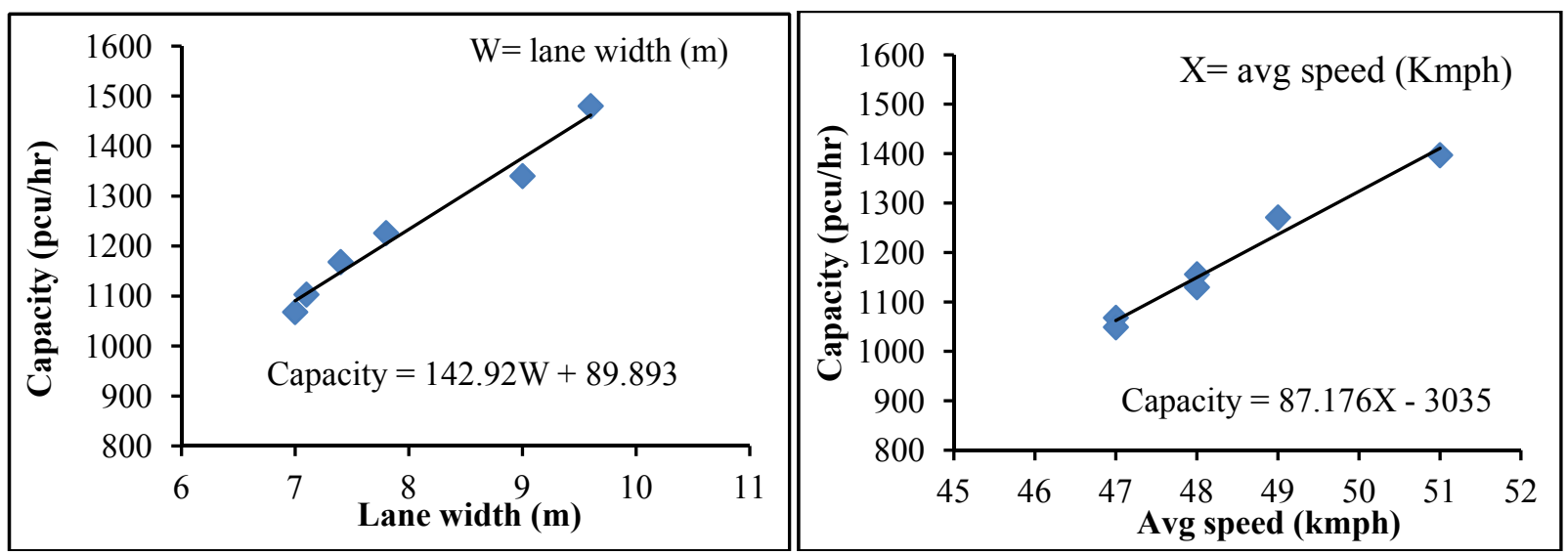

Fig. 10 Capacity vs. lane width and average speed at horizontal curve portion.

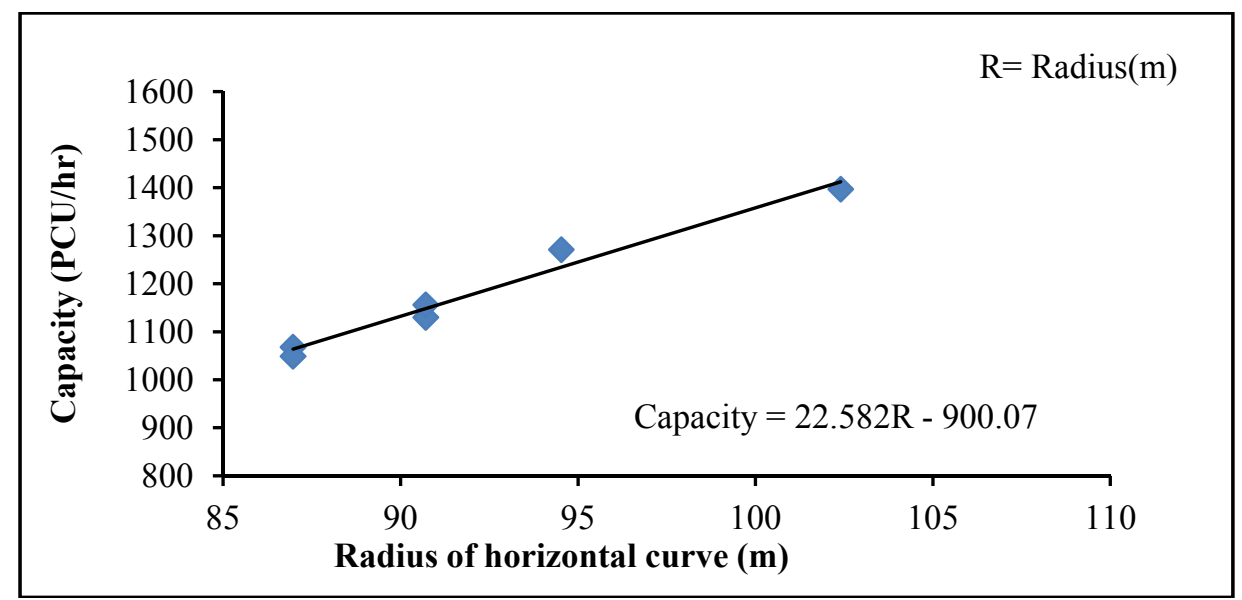

Fig. 11 Capacity vs. radius at horizontal curve portion. 
Table 3 Capacity of road with different lane width.

\begin{tabular}{|c|c|c|c|c|c|c|c|}
\hline \multirow{2}{*}{ Portion } & \multirow{2}{*}{$\begin{array}{l}\text { Category of } \\
\text { road }\end{array}$} & \multirow{2}{*}{ Section } & \multirow{2}{*}{$\begin{array}{l}\text { Carriageway } \\
\text { width }(\mathrm{m})\end{array}$} & \multicolumn{2}{|c|}{ Capacity (PCU/hr) } & \multirow{2}{*}{$\begin{array}{l}\text { \% Difference of } \\
\text { Chandra and Linear } \\
\text { Regression method }\end{array}$} & \multirow{2}{*}{$\begin{array}{l}\text { Avg speed } \\
\text { (kmph) }\end{array}$} \\
\hline & & & & Chandra method & Linear Regression & & \\
\hline \multirow{6}{*}{ Straight } & \multirow{3}{*}{ NH209 } & I & 7.1 & 1103 & 1105 & 0.15 & 55 \\
\hline & & II & 7.2 & 1168 & 1148 & 1.79 & 56 \\
\hline & & III & 7.1 & 1068 & 1090 & 2.05 & 54 \\
\hline & \multirow{3}{*}{ NH206 } & IV & 9.6 & 1480 & 1462 & 1.24 & 59 \\
\hline & & $\mathrm{V}$ & 9.0 & 1340 & 1376 & 0.03 & 58 \\
\hline & & VI & 7.8 & 1226 & 1205 & 1.77 & 56 \\
\hline \multirow{6}{*}{$\begin{array}{l}\text { Horizontal } \\
\text { curve }\end{array}$} & \multirow{3}{*}{ NH209 } & I & 7.4 & 1068 & 1075 & 1.06 & 47 \\
\hline & & II & 7.6 & 1130 & 1104 & 2.34 & 48 \\
\hline & & III & 7.2 & 1049 & 1055 & 0.54 & 47 \\
\hline & \multirow{3}{*}{ NH206 } & IV & 9.8 & 1397 & 1377 & 1.47 & 51 \\
\hline & & $\mathrm{V}$ & 9.2 & 1271 & 1302 & 2.41 & 49 \\
\hline & & VI & 8.0 & 1156 & 1154 & 0.20 & 48 \\
\hline
\end{tabular}

The equations obtained are as follows:

Capacity (based on lane width) at curved portion $=$ 142.92 (lane width) +89.893

Capacity (based on lane width) at straight portion $=$ 123.86 (lane width) +162.87

Capacity (based on average speed) at curved portion $=87.176$ (Avg. speed) -3035

Capacity (based on Average speed) at straight portion $=81.885$ (Avg. speed) -3382

Capacity (based on horizontal curve radius) $=22.582$ (radius of curve) - 900.07

The capacity obtained from Satish Chandra method and capacity obtained from linear regression equation has been compared and the variation is found to be very marginal as the maximum difference is $2.41 \%$ as shown below:

\section{Conclusions}

Based on field observations and analysis carried out on both the national highways following conclusions are drawn:

Collected geometric details and compared the width of carriageway, shoulder and its conditions as it may affects capacity of a road.

The calculated PCU values as per Chandra's method at various sections on highways may have marginal difference with the values recommended by IRC and we considered these values to estimate capacity.
It is found that with the increase in lane width, speed and radius of horizontal curve, PCU value also got increased.

Attempts has been made to develop linear regression equation and compared with the capacity values as we got using Chandra's method. In most of the cases the error is observed to be less than $3 \%$. The percentage error is in the range between 0.02 and 2.41 which is very marginal.

It has been observed that increase in lane width and radius of curves obviously increases the capacity their by increases both comfort and safety of the road users.

\section{Scope of Future Work}

Attempts may be taken to calculate PCU values and capacity by considering effect of shoulder width, roughness, gradients, intersections, driver behavior (physical and psychological) etc.

Development of models is to estimate capacity at different sections of roads by considering more number of national highways.

\section{References}

[1] Chandra, S., and Kumar, U. 2003. "Effect of lane width on Capacity under Mixed Traffic Condition in India.” DOI: 10.1061/ ASCE 0733-947X 2003 129: 2-155.

[2] Khanorkar, A. R., Ghodmare, S. D., and VKhode, B. 2014. "Impact of Lane Width of Road on Passenger Car Unit Capacity under Mix Traffic Condition in Cities on 


\section{Two Lane Undivided National Highways}

Congested Highways." IJERA 4 (5): 180-4.

[3] Kamplimath, H. M. 2016. "Capacity Estimation for a Two Lane Undivided Carriageway-A Case Study for National Highway -63.” May 15, 2016, ISBN: 978-81-932074-8-2 (ICSTM-16), IIC New Delhi, www.Conferenceworld.in.

[4] Mathew, T. V. 2014. (IIT Bombay -2014) "Estimation of Point.” Transportation Systems Engineering.

[5] Fitzpatrick, K., Schneider IV, W. H., and Park, E. S. 2018. "Summary of Comparison of Crashes on Rural Two-Lane and Four-Lane Highways." http://ti.tamu.edu/documents/o-4618-1.pdf.

[6] Farouki and Nixon. 1976. "The Effect of Width of
Suburban Roads on the Mean Free Speeds of Car." Traffic Engineering Control 17 (12): 518-9.

[7] Shalkamy, A., Said, D., and Radwan, L. 2015. “ Influence of Carriageway Width and Horizontal Curve Radius on Passenger Car Unit Values of Two Lane Two Way Rural Roads." Civil and Environmental Research 7 (3).

[8] Yagar and Aerede. 1983. "Geometric and Environmental Effects on Speeds of 2-lane highways." Transportation Research-A 17A (4): 315-25.

[9] Tara Gin and Eckhart. 1953. "The Effect of Shoulder on Speed and Lateral Placement of Motor Vehicles." $H B$ Proceedings, Vol.32, PP. 371-82. 